\title{
Viscum Album Modulates Apoptotic Related Genes in Melanoma Tumor of Mice
}

\author{
Anamaria da Silva Facina ${ }^{*}$, Gil Facina², Ismael Dale Cotrim Guerreiro da Silva², \\ Giovana Aparecida Gonçalves ${ }^{2}$, Fernando Augusto de Almeida1, \\ Silvana Aparecida Alves Corrêa de Noronha ${ }^{3}$, Samuel Marcos Ribeiro de Noronha ${ }^{3}$, \\ Mary Uchiyama Nakamura ${ }^{4}$ \\ ${ }^{1}$ Departament of Dermatology, Federal University of São Paulo, São Paulo, Brazil \\ ${ }^{2}$ Department of Gynecology, Federal University of São Paulo, São Paulo, Brazil \\ ${ }^{3}$ Department of Surgery, Federal University of São Paulo, São Paulo, Brazil \\ ${ }^{4}$ Departament of Obstetrics, Federal University of São Paulo, São Paulo, Brazil \\ Email: dermatologista@hotmail.com
}

Received 4 February 2014; revised 2 March 2014; accepted 20 March 2014

Copyright (C) 2014 by authors and Scientific Research Publishing Inc.

This work is licensed under the Creative Commons Attribution International License (CC BY). http://creativecommons.org/licenses/by/4.0/

(c) (i) Open Access

\section{Abstract}

Cancer is a major public health problem throughout the world. It is estimated that one third of the American population will develop the disease at some time during their lifetimes. Among these, melanoma will account for $7 \%$ of the cases. In Brazil, in 2012 , it is estimated that over six thousand new melanoma cases occurred. During recent years, the incidence of melanoma has increased, mainly due to a more constant exposure of the skin to sunlight. In this work, our aim is to assess the expression of apoptotis-related genes melanoma tumors in mice treated with Viscum album (VA). This will allow us to better understand the molecular mechanisms underlying tumor cell death activation caused by this compound. Our results clearly demonstrate upregulation of pro apoptotic genes (Trp53bp2, Nol3, Fadd, Tnfsf10, Traf1, Traf2, Cflar, Card10, Nod1, Casp 2, Casp7, Xiap, Dad1, and Dffb). Further bioinformatics-based tool analysis allowed us to assess which specific cell death-related intracellular pathways were activated by VA treatment. Two major effects of VA in melanoma cells could be observed: generation of an immunomudulatory Th-1 like action, recruiting several interleukines, and cell death activation through Caspase7, associated uspstream with Card10 and downstream with CAD. In summary, VA modulates apoptosis related genes in cancer melanoma cells. Although a deeper study should be conducted, VA seems to interfere with important signaling pathways within melanoma cells that control the cellular mechanisms of apoptosis activation. Therapeutic approaches using VA as an antineoplastic and adjuvant medication compounding should be considered.

\footnotetext{
*Corresponding author.
} 


\section{Keywords}

\section{Viscum Album; Melanoma; Apoptosis Pathways; PCR Array; Immunohistochemistry}

\section{Introduction}

In the United States, approximately 1 million people are being treated for melanoma, and the incidence estimates for the disease are over 76 thousand new cases in 2012. The average age of these patients is 63 years for men and 56 for women. Fortunately, 84\% of diagnosed cases are confined to the primary site, or have a high potential for cure [1]. In Brazil, over 6 thousand new melanoma cases were estimated to occur in 2014. The highest rates of the disease are found in the southern part of the country, which is responsible, along with the southeastern part, for $82 \%$ of new cases [2]. The median overall survival for all stages is $91.2 \%$ and $89.1 \%$, respectively, after 5 and 10 years [1].

Clinically melanoma is characterized by pigmented lesions displaying color change (black, brown, pink or white), asymmetry and irregular borders. Usually these moles measure more than six millimeters in diameter and are histologically classified as superficial spreading, nodular, lentigo maligna or acral lentiginous and desmoplastic [3].

Despite an intense search for curative treatments for late-diagnosed malignant melanoma, the results are still very limited [4]. Chemotherapy alone or in combination with radiotherapy has been ineffective in prolonging survival. Upcoming approaches to treating malignant melanoma rely on immunotherapy [5] [6]. Thus far, there is no ideal immunotherapeutic option to treat melanoma, although new drugs that fight cancer through immunooncological mechanisms are under development, with a particular focus on the molecular mechanism of apoptosis.

Herbal extracts are sometimes used as complementary therapies for melanoma. In Europe, 15\% - 73\% of patients have received complementary alternative medicines as part of their treatment [7], and it is an especially prevalent practice in German-speaking countries [8] [9]. In particular, the extract of Viscum album (VA), which has been used for over 80 years, shows good results in some studies [10]-[12].

VA (also called mistletoe) is a hemiparasite medicinal plant, from the Lorentaceae family, hosted by several trees in Europe, Africa and Asia. It has different therapeutic properties, which arise from the molecular interactions of lectins and viscotoxins with different cellular components. Binding of lectins to polysaccharides on the outer cell membrane leads to immunomodulatory activity while both lectins and viscotoxins contribute to cytotoxicity [13].

Currently, there is insufficient evidence to indicate VA as a therapy [14]. However, recent studies have suggested that VA is able to increase the proliferation T-helper (CD4) and Natural-Killer cells, as well as stimulate release of CD4-endorphins and lymphokines by macrophages, pro-inflamatory cytokines, and prostaglandin [15]-[19]. Furthermore, VA was able to downregulate central gens involved in malignancy in glioblastoma cells [20].

This being the case, the objective of this work is to assess the expression of apoptotis-related genes in melanoma tumors after VA treatment, in order to better understand the molecular mechanisms underlying the apoptotic activation of melanoma tumor cells by VA.

\section{Materials and Methods}

\subsection{Experimental Animals}

A total of 12 female mice (Mus musculus domesticus), strain C57BL/6N, were used in this work. They were 8 weeks old and weighed approximately $25 \mathrm{~g}$ each. They were purchased from CEDEME-UNIFESP (Centro de Desnvolvimento de Modelos Experimentais-UNIFESP). Mice were housed in standard laboratory conditions of 12:12 light:dark cycle and regulated temperature and humidity. Regular chow and water were available ad libidum. All procedures were conducted according to the guidelines in "Principles of ethical and practical of laboratory animal care" (UNIFESP) and were approved by the ethics committee in the University in São Paulo (CEP 0574/102). 


\subsection{Experimental Groups}

The mice were allocated into two different experimental groups. The control-group $(n=6)$ received a subcutaneous implant of tumor cells (see below for methods) followed by injections of distilled water. This group is used to ensure that the data reflect the effects of the experiment itself and not the stress factor of injections. The VA-treated group $(n=6)$ received subcutaneously implants of tumor cells followed by peritumoral injections of VA (0.1 ml per injection) which were administered subcutaneously for 19 days. Injections were given around the area that had been shaved for the injection of the B16F10 cell graft.

\subsection{Tumor Cell Culture and Implant Procedure}

The melanoma cell line B16F10 was cultured in RPMI 1640 medium (Gibco, Carlsbad-CA) (made up of 10.00 $\mathrm{g}$ of RPMI, $2.00 \mathrm{~g}$ of sodium bicarbonate, $2.33 \mathrm{~g}$ of HEPES and $80.0 \mathrm{mg}$ of garamicine diluted in $1.0 \mathrm{~L}$ of usp water) $\mathrm{pH} 7.3$ and supplemented with $10 \%$ of fetal bovine serum (Gibco, Carlsbad-CA). Cells were grown in $\mathrm{T}-25$ flasks in an incubator at $37^{\circ} \mathrm{C}, 5 \% \mathrm{CO}_{2}$. Cell flasks were checked daily and had their medium changed every $72 \mathrm{~h}$.

Tumor cells ( $5 \times 10^{4}$ BF16-F10 cells suspended in PBS), were injected subcutaneously into the right dorsum of each female mouse using an insulin syringe. Sham (distilled water) or VA treatment was begun on the same day as tumor cell implantation.

\subsection{Viscum album Preparations}

VA Qu Spez was imported from WELEDA (Switzerland) by FAPESP, Sao Paulo, Brazil. We decide to use VA Qu Spez because it is made for therapeutic use, and thus contains standardized levels of both lectins and viscotoxins, thereby permitting comparisons to published literature. Viscum album Qu (Iscador Qu $5 \mathrm{mg}$ special) contains $0.375 \mathrm{ng}$ of lectin per ml. We calculated the Viscum album's dose as Van Huyen et al. (2006) based on the lectins dosage that they had used [18].

\subsection{Tumor Mass Collection}

On day nineteen, animals were sacrificed for tumor mass harvesting. First, the mice were anesthetized with 0.3 $\mathrm{mL}$ of xylazine (Anasedan ${ }^{\circledR}$ ) and $0.5 \mathrm{~mL}$ of ketamine (Dopalen $\left.{ }^{\circledR}\right)$. The mice were then exsanguinated via intracardiac puncture, in order to collect blood for separate study (Facina et al, unpublished data). The tumor mass was then removed through a toraco-laparotomy, Tumor masses were kept in minitubes and maintained in liquid nitrogen for later processing.

\subsection{RNA Extraction, Purification and Measurement}

RNA was extracted from the tumor masses using TRIzol Reagent (Invitrogen, Foster City, CA) following the manufacturer's instructions. The precipitated RNA from the aqueous phase was washed with $75 \%$ ethanol. The RNA was dried and dissolved in RNase-free water. Total RNA was then purified with Qiagen RNeasy MiniKit (Qiagen, Valencia, CA) and submitted to DNAse treatment. The amount and quality of the extracted RNA were assessed by spectrophotometry using NanoDrop v3.3.0 (NanoDrop Technologies Inc., Rockland, DE) and by the capillary electrophoresis system 2100 Agilent Bioanalyzer (Agilent Technologies, Palo Alto-CA) respectively.

\section{7. qPCR Array}

The Mouse Apoptosis RT ${ }^{2}$ ProfilerTM PCR Array (SA Biosciences) was used for gene expression analysis. It allows the simultaneous analysis of 84 genes involved in the regulation of apoptosis. Total RNA was extracted from tumor masses and qualitatively tested through 2100 Bioanalizer (Agilent Technologies, Palo Alto CA) according to the manufacturer's instructions. Each total RNA sample added to qPCR reactions (control and treatment) was obtained from six animals and a pool was prepared in triplicate from each animal. In each group, $1 \mu \mathrm{g}$ of total RNA (for plate) were used to convert cDNA via reverse transcriptase reaction using the First Strand kit (SABiosciences, Qiagen), according to the manufacturer's instructions. A cocktail containing cDNA and all the optimized reagents and buffers needed for SYBR ${ }^{\circledR}$ Green were prepared based upon real-time polymerase chain reactions. Twenty-five microliters of this experimental cocktail were added to each well on the 96-well plate, 
which was then loaded into a 7500 Fast Real-Time PCR System (Applied Biosystems) and run in a two-step cycling program, with one initial cycle of $95^{\circ} \mathrm{C}$ for $10 \mathrm{~min}$ and 40 cycles of $15 \mathrm{~s}$ at $95^{\circ} \mathrm{C}$ and $1 \mathrm{~min}$ at $60^{\circ} \mathrm{C}$.

\subsection{Immunohistochemistry Assays}

Tumoral cells were collected in neutralized formalin. The tissue was paraffin embedded and $5 \mu \mathrm{m}$ sections were prepared on polylysine coated glass slides from all tumors mass specimens. Immunohistochemical staining using anti-mouse Akt1 and anti-mouse Bcl2 (Abcam Inc., Cambridge, MA, USA). Immunohistochemical staining was performed using a standard polymer-peroxidase technique (Dako, Carpinteria, CA, USA). After deparaffination, rehydration and blockade of endogenous peroxidase activity, heat-induced antigen retrieval was performed in Tris-EDTA buffer ( $\mathrm{pH}$ 9.0). After antigen retrieval sections were covered with serum-free protein block (Dako) for $1 \mathrm{hr}$, followed by incubation with anti-human Foxp3 (e-biosciences, San Diego, USA) for $1 \mathrm{hr}$ and EnVision1 anti-mouse/horseradish peroxidase (HRP) polymer (Dako) for $30 \mathrm{~min}$ at room temperature. Color was developed using diaminobenzidine (DAB1) chromogen system.

\subsection{Statistical Analysis and Data Treatment}

qPCR reactions were analyzed through the online software RT2 Profiler PCR Array Data Analysis (SABiosciences). Descriptive statistics (means and standard deviation) and inferencial statistics were obtained through the Student's t-test, with significance level of $5 \%(p>0.05)$.

Quantification Cycle values (qC) obtained were processed in a web-based software for arrays hosted by the SA Biosciences website (a Qiagen company) called RT2 ProfilerPCR Array Data Analysis version 3.5 (http://pcrdataanalysis.sabiosciences.com/pcr/arrayanalysis.php). This software allows uploading of Excel files containing $\mathrm{qC}$ values for each group, in order to obtain the following parameters: average $\mathrm{qC}$ values, average $\Delta \mathrm{qC}$ fold change values, $\mathrm{p}$ values, fold regulation values, heat maps, scatter plots and clustergrams. We only considered p values below 0.05 and fold regulation values higher than 2.00 to be statistically significant.

\section{Results}

\subsection{PCR Array Analysis}

In general, VA upregulated the expression of the genes related to apoptosis. The compound affected expression of $31 \%$ of the genes in the plate when using the control group as a calibrator. No gene was downregulated by VA. Major changes (cut-off $>2.0$ fold) were observed in the following genes: Traf1, Dad1, Dffb, Trp53bp2, Casp7, Xiap, Cflar, Nol3, Nod1, Card10, Tnfsf10 and Traf2 (Figure 1).

Moreover, different intracellular apoptotic pathways were activated by VA in the tumoral mass cells, such as intrinsic and extrinsic pathways, the caspase family and fragmentation factors. However the main pathway activated by VA was the extrinsic apoptosis pathway, which is composed, among others, by the following genes

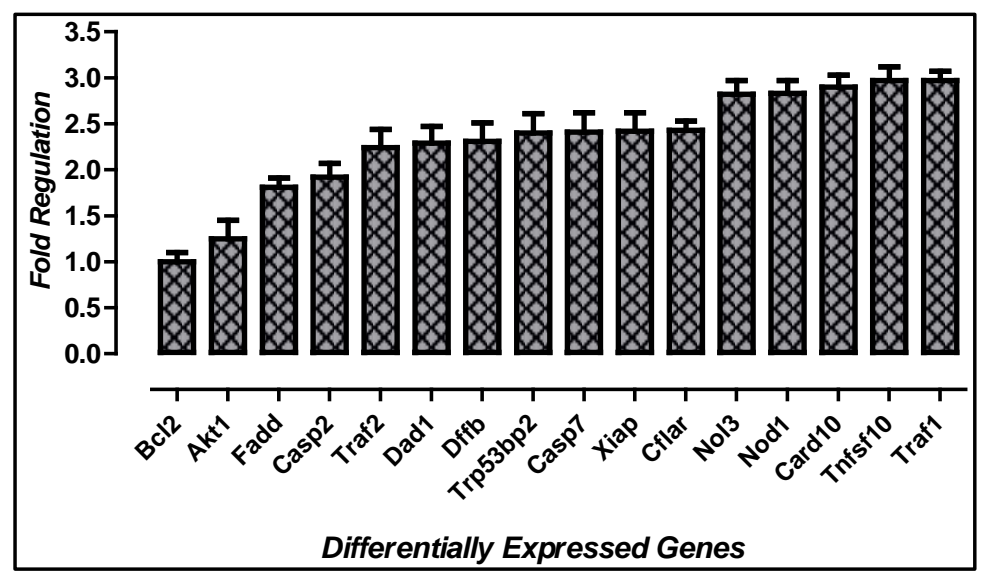

Figure 1. Differentially expressed genes after treatment with VA when compared to control without treatment. P values $<0.05$. 
Nol3, Fadd, Tnfsf10, Traf1, Traf2 and Cflar. All of these genes were upregulated by the treatment. The hallmark of apoptotic cell death $D f f b$ (DFF40/CAD endonuclease) was upregulated.

\subsection{Immunohistochemistry}

The immune-histochemistry assays showed the validation to the gene express assay by means qPCR. We chose an important protein for validation, Akt1. The gene expression of this protein was not altered after qPCR analysis (fold regulation was 1.25). When comparing control and VA treated tumor cells using monoclonal antibody against this protein, no difference was observed [\% of cells: $28.4 \pm 7.5$ (control) and $33.8 \pm 4.96$ (VA), p = 0.32, $\mathrm{N}=5$; Student's t test] (Figure 2).

\subsection{MetaCore ${ }^{\mathrm{TM}}$ Analysis}

Differentially expressed genes were associated with canonical pathways and provided us apoptosis related gene networks. MetaCore ${ }^{\mathrm{TM}}$ (Thomson Reuters) analysis generated four different networks: Most genes were associated with the group of apoptosis stimulators when compared to others groups (Figure 3).

Network 1 (NW1) is composed of the genes RINT-1, RCC1, dynamin, KNSL1, and CKS2. This network is related to the following GO processes: regulation of apoptotic process $(65.0 \% ; 1.145 \mathrm{e}-10)$, regulation of programmed cell death $(65.0 \% ; 1.262 \mathrm{e}-10)$, regulation of cell death $(65.0 \% ; 1.886 \mathrm{e}-10)$, cell cycle $(60.0 \%$; $3.036 \mathrm{e}-10)$, and the apoptotic process $(55.0 \% ; 5.482 \mathrm{e}-10)$ (Data not shown).

NW2 is composed of the genes TRAF1, c-FLIP $(L), N F-k B$ p50/p65, ICAM1, and CD80. This network is related to the following GO processes: regulation of cytokine production $(56.9 \% ; 1.938 \mathrm{e}-34)$, positive regulation of response to stimulus $(72.5 \% ; 2.214 \mathrm{e}-33)$, positive regulation of biological process $(96.1 \% ; 3.020 \mathrm{e}-32)$, immune response $(66.7 \% ; 7.775 \mathrm{e}-32)$, and positive regulation of immune system processes $(58.8 \% ; 2.409 \mathrm{e}-31)$ (Data not shown).
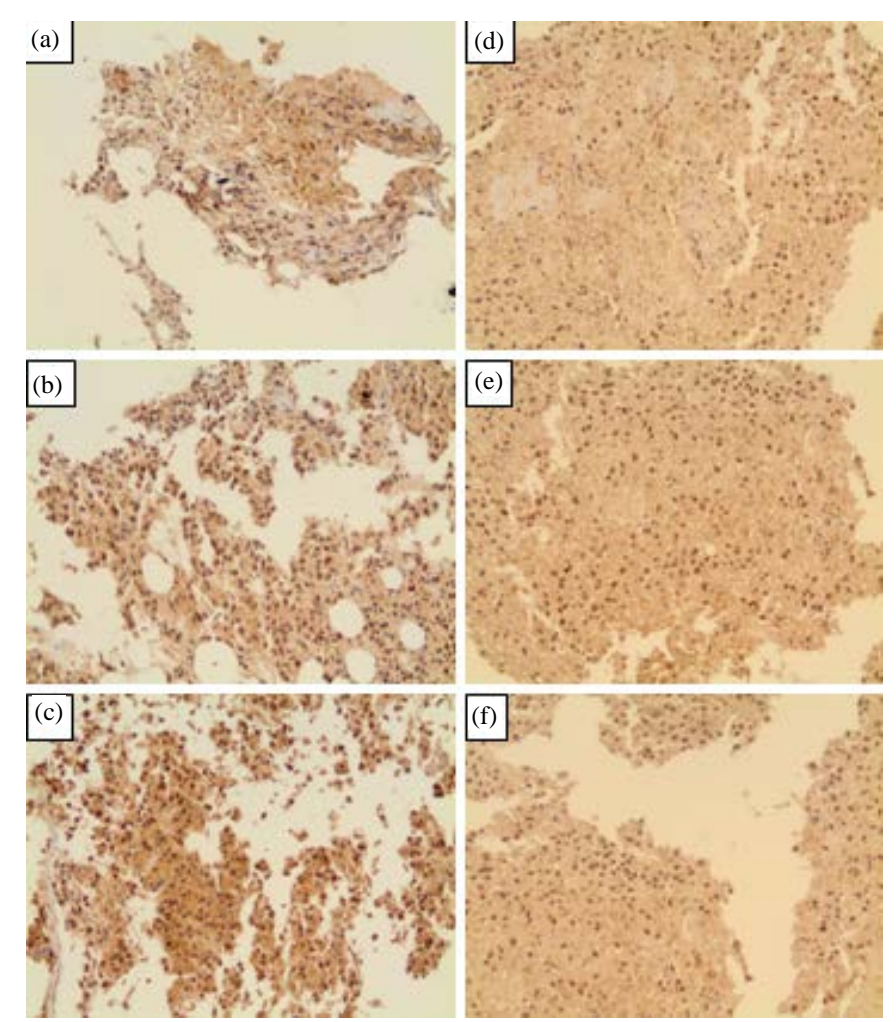

Figure 2. Immuno-histochemical analysis using monoclonal antibody against AKT1 protein after treatment with VA when compared to control without treatment. (a) (b) and (c): Three Different fields for control; (d) (e) and (f):Three Different fields for VA treatment. 

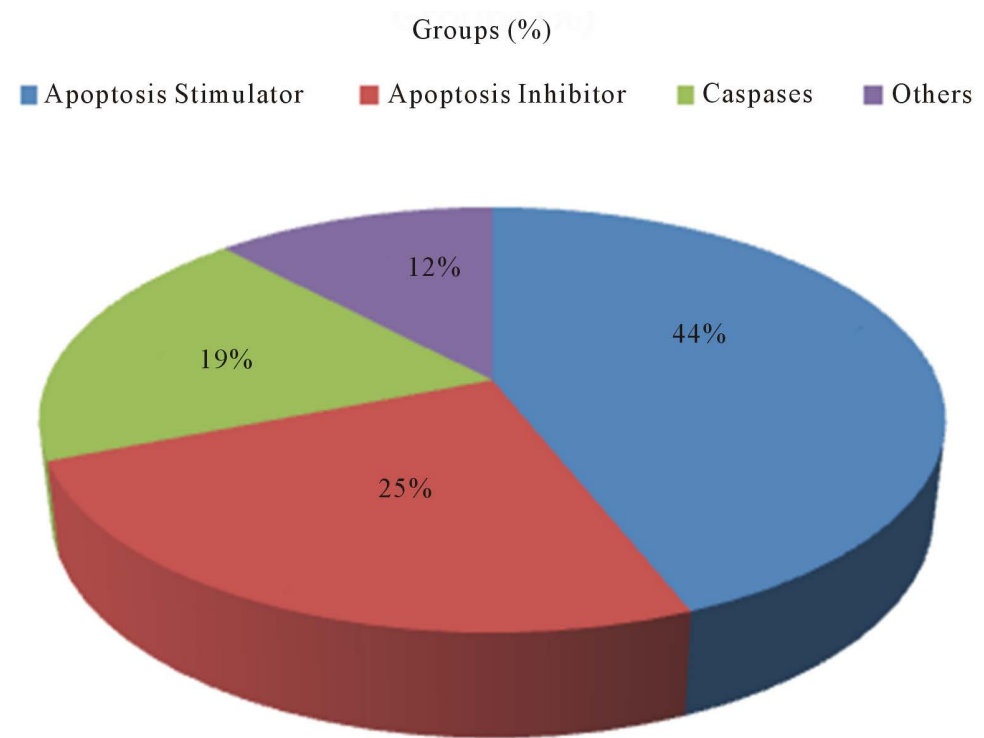

Figure 3. Percentage distribution by groups of genes related to the apoptosis pathways.

NW3 is composed of the genes IFN-beta, IFN-alpha, double-stranded RNA, Virus ssRNA extracellular region, and TANK. This network is related to the following GO processes: negative regulation of type I interferon production (53.3\%; 1.336e-19), regulation of type I interferon production $\left(60.0 \%\right.$; $1.971 \mathrm{e}^{-19)}$, positive regulation of interferon-alpha production $(40.0 \%$; $8.498 \mathrm{e}-19)$, and regulation of innate immune response $(73.3 \%$; $1.915 \mathrm{e}-18)$, and negative regulation of cytokine production $(66.7 \% ; 2.804 \mathrm{e}-18)$.

NW4 is composed of the genes DAD1, BLIMP1 (PRDI-BF1), PAX5, and XBP1. This network is related to the following GO processes: epithelial cell maturation involved in salivary gland development $(25.0 \%$; $1.804 \mathrm{e}-04)$, serotonin secretion, neurotransmission $(25.0 \% ; 1.804 \mathrm{e}-04)$, epithelial cell differentiation involved in salivary gland development (25.0\%; 3.608e-04), cell differentiation involved in salivary gland development $(25.0 \%$; $5.412 \mathrm{e}-04)$, and positive regulation of endoplasmic reticulum unfolded protein response $(25.0 \%$; $7.215 \mathrm{e}-04)$.

\subsection{Tumor Volume Analysis}

We observed no statistically significant differences in tumor volume between the sham-operated and VA-treated groups $(\mathrm{p}=0.4846)($ data not shown).

\section{Discussion}

In general, the apoptosis-related gene expression profile, here obtained, clearly demonstrates that VA exerts a modulator effect on melanoma cells. This effect has an important role in driving the tumor cells to apoptosis, by specifically activating the extrinsic apoptosis pathway.

Hamsa \& Kuttan observed a decrease in the expression of Bcl-2 and an increased expression of the following pro-apoptotic genes p53, caspase-3, 8, 9, BID and BAX in B16-F10 melanoma cells treated with an alkaloid as opposed to VA. They suggested that both the intrinsic and the extrinsic apoptosis pathways were activated by the alkaloid compound [21]. Another study with toxic lectin in Lymphoma cells showed similar results [22]. Although Trp53bp2 (alias: ASPP2) gene expression was increased by VA, no change was observed for the Bax gene (pro-apoptotic gene) which is induced by p53 and links to the Bcl family [23]. Tumor suppressor p53, frequently mutated in cancers, is a tetrameric multidomain transcription factor, which bind to proteins of the ASPP family. ASPP2, which seems to regulate selectively the apoptotic function, and not the cell-cycle, is upregulated [24].

Our protocol demonstrated activation of TNFsf10 (Alias: TRAIL), TRAF1, TRAF2 and FADD and subsequent activation of Cflar and Nol 3. These genes translate members of the extrinsic apoptosis pathway. Nol-3 (alias: ARC), an anti-apoptitic protein, is responsible for blocking both extrinsic and intrinsic apoptosis pathways [25]. TNF is a cytokine that has an important role in the cell cycle, as well as in cell proliferation, differentiation, sur- 
vival and death. TNF acts on cells through two different membrane-bound receptors, TNFR1 (tumor necrosis factor receptor 1) and TNFR2 (tumor necrosis factor receptor 2): however, most of the known biological activities of TNF are triggered by the TNFR1 [26]. TRAF1 and TRAF2 (TNF receptor-associated factor1 and 2) preferentially form 1:2 heterotrimers that interact with cIAP [27]. CIAP has a BIR domain that interacts with XIAP and other components [28]. The death ligand TRAIL induces apoptosis by formation of DISC (death-inducing signaling complex) and recruitment of the adapter molecule FADD [27] [29].

McLornan et al. suggest that CFLAR (Long) mRNA expression may play a prognostic role in adult acute myeloid leukemia [30]. CFLAR is the main antipapoptotic resistance factor regulator in the extrinsic pathway [31]. ARC antagonizes the extrinsic pathway blocking DISC assembly through Fas, FADD, and procaspase 8 cascade activation. This leads the cell to inhibit the intrinsic pathway by blocking BAX and p53 transcriptional function [32].

Activation of caspase 8 is an ordinary action of VA [15]. Other authors have reported the absence of caspase 8 with use of lectins [22] [33]. Caspase 8 is in the end of extrinsic apoptotic pathway as well as in the beginning of initiator caspases [34]. In our work, the gene for caspase 8 was not differentially expressed after VA treatment. Another important group of differentially expressed genes triggered by VA treatment in melanoma cells was caspase 2, caspase 7, Nod1 and Card-10. Apoptosis induction by IFN- $\beta$ in association with caspase 2 has already been demonsrated and caspase 2 has been suggested as a possible measurable marker in melanoma [35]. Drugs like etoposide are able to induce apoptosis, where caspase-2 acts as an upstream activator of mitochondrial release of cytochrome c. This being the case, it seems like caspase 2 acts as a mitochondrial pathway effector [36]. Altogether, we believe that caspase 2 is produced as the result of the integration of different effects of VA.

Manon et al. observed that Nod1 might interact with Card-10 in order to activate NF- $\kappa \mathrm{B}$ [37]. CARD gene family members are divided into two big groups, one activated by caspases and one activated by NF- $\kappa \mathrm{B}$ [38]. Caspase-7 is an effector caspase, although it usually requires caspase-1 activity for its own activation in "inflammasomes" [39] [40]. The inflammasome composition depends on the type of bound nucleotides and also on oligomerization domains (NOD). This being the case, our study clearly demonstrates that VA triggers a very specific response in melanoma cells, while the compound employed by Hamsa \& Kuttan activated both apoptosis pathways [41].

In addition, we also observed that the XIAP gene (X-linked inhibitor of apoptosis) was overexpressed by the treatment. XIAP is known for inhibiting caspase 3 e 9 through BIR domains [42]. Specific alterations of the BIR domain in XIAP render inhibition of caspases 3 and 7 to be ineffective [43]. Curiously, it could also be observed that $D a d-1$ and $d f f b$ were overexpressed by VA treatment in melanoma cells. Lindhom et al. reported that dysfunction of Dad-1 gene (cell death defense molecule) is connected to programmed cell death. DAD 1 is a subunit of the oligosaccharytransferase complex, located in the Endoplasmatic reticulum membrane [44]. Dad1 is associated with Neuroencocrine tumor risk [45].

Previous studies have revealed that DNA fragmentation in apoptosis is mediated by a heterodimeric complex composed of DFFa and DFFb. This heterodimer undergoes cleavage by an effector caspase and eventually enters the nucleus and degrade chromosomal DNA fragmentation [46]. In another previous study, Kim et al. demonstrated that caspase 7 could alone induce DNA fragmentation and activate CAD under some special conditions [47].

\section{Conclusions}

In summary, our results demonstrate that VA drives melanoma cells to programmed cell death, possibly through activation of the extrinsic apoptotic pathway, but certainly not by activating the intrinsic pathway. Cell death induction seems to be activated by Caspase 7 in a specific manner, perhaps by recruiting nod- 1 in association upstream with card-10 and downstream with CAD.

In summary, VA modulates apoptosis related genes in cancer melanoma cells. Although a deeper study should be conducted, VA seems to interfere with important signaling pathways within melanoma that control the cellular mechanisms of apoptosis activation. Therapeutic approaches using VA as an antineoplastic and adjuvant medication compounding should be considered.

\section{Acknowledgements}

The work was supported by grant number 2010/135938-6 from the Sao Paulo Research Foundation (FAPESP)Brazil. 


\section{References}

[1] Siegel, R., DeSantis, C., Virgo, K., Stein, K., Mariotto, A., Smith, T., et al. (2012) Cancer Treatment and Survivorship Statistics. CA: A Cancer Journal for Clinicians, 62, 220-241. http://dx.doi.org/10.3322/caac.21149

[2] Instituto Nacional de Câncer (2012) Estimativa 2012. http://www2.inca.gov.br/wps/wcm/connect/tiposdecancer/site/home/pele_melanoma/definicao

[3] Bonfa, R., Bonamigo, R.R., Bonfa, R., Duro, K.M., Furian, R.D. and Zelmanowicz, A.M. (2011) Early Diagnosis of Cutaneous Melanoma: An Observation in Southern Brazil. Anais Brasileiros de Dermatologia, 86, 215-221.

[4] NCCN Melanoma Practice Guidelines. National Comprehensive Cancer Network. NCCN Guidelines Version 1.2013 Staging. Melanoma Table of Contents. Discussion. (2012) Ref Type: Internet Communication.

[5] Eigentler, T.K., Caroli, U.M., Radny, P. and Garbe, C. (2003) Palliative Therapy of Disseminated Malignant Melanoma: A Systematic Review of 41 Randomised Clinical Trials. The Lancet Oncology, 4, 748-759. http://dx.doi.org/10.1016/S1470-2045(03)01280-4

[6] Veronesi, U., Adamus, J., Aubert, C., Bajetta, E., Beretta, G., Bonadonna, G., et al. (1982) A Randomized Trial of Adjuvant Chemotherapy and Immunotherapy in Cutaneous Melanoma. The New England Journal of Medicine, 307, 913-916. http://dx.doi.org/10.1056/NEJM198210073071503

[7] Molassiotis, A., Fernadez-Ortega, P., Pud D, Ozden G., Scott , J.A., Panteli, V., et al. (2005) Use of Complementary and Alternative Medicine in Cancer Patients: A European Survey. Annals of Oncology, 16, 655-663. http://dx.doi.org/10.1093/annonc/mdi110

[8] Laengler, A., Spix, C., Seifert, G., Gottschling, S., Graf, N. and Kaatsch, P. (2008) Complementary and Alternative Treatment Methods in Children with Cancer: A Population-Based Retrospective Survey on the Prevalence of Use in Germany. European Journal of Cancer, 44, 2233-2240. http://dx.doi.org/10.1016/j.ejca.2008.07.020

[9] Eustachi, A., Pajtler, H., Linde, K., Melchart, D. and Weidenhammer, W. (2009) Patients of an Interdisciplinary Cancer Treatment Center: Use of, Knowledge about, and Demand for CAM Treatment Options. Integrative Cancer Therapies, 8, 56-62. http://dx.doi.org/10.1177/1534735408327996

[10] Thies, A., Dautel, P., Meyer, A., Pfuller, U. and Schumacher, U. (2008) Low-Dose Mistletoe Lectin-I Reduces Melanoma Growth and Spread in a Scid Mouse Xenograft Model. British Journal of Cancer, 98, 106-112. http://dx.doi.org/10.1038/sj.bjc.6604106

[11] Kienle, G.S., Grugel, R. and Kiene, H. (2011) Safety of Higher Dosages of Viscum album L. in Animals and HumansSystematic Review of Immune Changes and Safety Parameters. BMC Complementary and Alternative Medicine, 11, 72. http://dx.doi.org/10.1186/1472-6882-11-72

[12] Kirsch, A. (2007) Successful Treatment of Metastatic Malignant Melanoma with Viscum album Extract (Iscador ${ }^{\circledR}$ M). The Journal of Alternative and Complementary Medicine, 13, 443-445. http://dx.doi.org/10.1089/acm.2007.6175

[13] Kienle, G.S., Berrino, F., Bussing, A., Portalupi, E., Rosenzweig, S. and Kiene, H. (2003) Mistletoe in Cancer-A Systematic Review on Controlled Clinical Trials. European Journal of Medical Research, 8, 109-119.

[14] Horneber, M.A., Bueschel, G., Huber, R., Linde, K. and Rostock, M. (2008) Mistletoe Therapy in Oncology. Cochrane Database of Systematic Reviews, 2, Article ID: CD003297.

[15] Khil, L.Y., Kim, W., Lyu, S., Park, W.B., Yoon, J.W. and Jun, H.S. (2007) Mechanisms Involved in Korean Mistletoe Lectin-Induced Apoptosis of Cancer Cells. World Journal of Gastroenterology, 13, 2811-2818.

[16] Lyu, S.Y. and Park, W.B. (2006). Mistletoe Lectin (Viscum album Coloratum) Modulates Proliferation and Cytokine Expressions in Murine Splenocytes. BMB Reports, 39, 662-670. http://dx.doi.org/10.5483/BMBRep.2006.39.6.662

[17] Seifert, G., Jesse, P., Laengler, A., Reindl, T., Luth, M., Lobitz, S., et al. (2008) Molecular Mechanisms of Mistletoe Plant Extract-Induced Apoptosis in Acute Lymphoblastic Leukemia in Vivo and in Vitro. Cancer Letters, 264, $218-228$. http://dx.doi.org/10.1016/j.canlet.2008.01.036

[18] Van Huyen, J.P., Delignat, S., Bayry, J., Kazatchkine, M.D., Bruneval, P., Nicoletti, A., et al. (2006) Interleukin-12 Is Associated with the in Vivo Anti-Tumor Effect of Mistletoe Extracts in B16 Mouse Melanoma. Cancer Letters, 243, 32-37. http://dx.doi.org/10.1016/j.canlet.2005.11.016

[19] Hegde, P., Maddur, M.S., Friboulet, A., Bayry, J. and Kaveri, S.V. (2011) Viscum album Exerts Anti-Inflammatory Effect by Selectively Inhibiting Cytokine-Induced Expression of Cyclooxygenase-2. PLoS One, 6, e26312. http://dx.doi.org/10.1371/journal.pone.0026312

[20] Podlech, O., Harter, P.N., Mittelbronn, M., Poschel, S. and Naumann, U. (2012) Fermented Mistletoe Extract as a Multimodal Antitumoral Agent in Gliomas. Evidence-Based Complementary and Alternative Medicine, 2012, Article ID: 501796. http://dx.doi.org/10.1155/2012/501796

[21] Hamsa, T.P. and Kuttan, G. (2011) Harmine Activates Intrinsic and Extrinsic Pathways of Apoptosis in B16F-10 Me- 
lanoma. Chinese Medicine, 6, 11. http://dx.doi.org/10.1186/1749-8546-6-11

[22] Ramnath, V., Rekha, P.S., Kuttan, G. and Kuttan, R. (2009) Regulation of Caspase-3 and Bcl-2 Expression in Dalton's Lymphoma Ascites Cells by Abrin. Evidence-Based Complementary and Alternative Medicine, 6, 233-238. http://dx.doi.org/10.1093/ecam/nem099

[23] Miyashita, T. and Reed, J.C. (1995) Tumor Suppressor p53 Is a Direct Transcriptional Activator of the Human Bax Gene. Cell, 80, 293-299.

[24] Trigiante, G. and Lu, X. (2006) ASPP [Corrected] and Cancer. Nature Reviews Cancer, 6, 217-226. http://dx.doi.org/10.1038/nrc1818

[25] Ao, J.E., Kuang, L.H., Zhou, Y., Zhao, R., Yang, C.M. (2012) Hypoxia-Inducible Factor 1 Regulated ARC Expression Mediated Hypoxia Induced Inactivation of the Intrinsic Death Pathway in p53 Deficient Human Colon Cancer Cells. Biochemical and Biophysical Research Communications, 420, 913-917. http://dx.doi.org/10.1016/j.bbrc.2012.03.101

[26] Wilson, N.S., Dixit, V. and Ashkenazi, A. (2009) Death Receptor Signal Transducers: Nodes of Coordination in Immune Signaling Networks. Nature Immunology, 10, 348-355. http://dx.doi.org/10.1038/ni.1714

[27] Rothe, M., Pan, M.G., Henzel, W.J., Ayres, T.M. and Goeddel, D.V. (1995) The TNFR2-TRAF Signaling Complex Contains Two Novel Proteins Related to Baculoviral Inhibitor of Apoptosis Proteins. Cell, 83, 1243-1252. http://dx.doi.org/10.1016/0092-8674(95)90149-3

[28] Guicciardi, M.E., Mott, J.L., Bronk, S.F., Kurita, S., Fingas, C.D. and Gores, G.J. (2011) Cellular Inhibitor of Apoptosis 1 (cIAP-1) Degradation by Caspase 8 during TNF-Related Apoptosis-Inducing Ligand (TRAIL)-Induced Apoptosis. Experimental Cell Research, 317, 107-116. http://dx.doi.org/10.1016/j.yexcr.2010.10.005

[29] Sprick, M.R. and Walczak, H. (2004) The Interplay between the Bcl-2 Family and Death Receptor-Mediated Apoptosis. Biochimica et Biophysica Acta, 1644, 125-132. http://dx.doi.org/10.1016/j.bbamcr.2003.11.002

[30] McLornan, D., Hay, J., McLaughlin, K., Holohan, C., Burnett, A.K., Hills, R.K., et al. (2012) Prognostic and Therapeutic Relevance of c-FLIP in Acute Myeloid Leukaemia. British Journal of Haematology, 16, 188-198.

[31] Miura, K., Fujibuchi, W. and Unno, M. (2012) Splice Variants in Apoptotic Pathway. Experimental Oncology, 34, 212217.

[32] Nam, Y.J., Mani, K., Ashton, A.W., Peng, C.F., Krishnamurthy, B., Hayakawa, Y., et al. (2004) Inhibition of Both the Extrinsic and Intrinsic Death Pathways through Nonhomotypic Death-Fold Interactions. Molecular Cell, 15, 901-912. http://dx.doi.org/10.1016/j.molcel.2004.08.020

[33] Narayanan, S., Surolia, A. and Karande, A.A. (2004) Ribosome-Inactivating Protein and Apoptosis: Abrin Causes Cell Death via Mitochondrial Pathway in Jurkat Cells. Biochemical Journal, 377, 233-240. http://dx.doi.org/10.1042/BJ20030797

[34] Elmore, S. (2007) Apoptosis: A Review of Programmed Cell Death. Toxicologic Pathology, 35, 495-516. http://dx.doi.org/10.1080/01926230701320337

[35] Kamiya, T., Okabayashi, T., Yokota, S., Kan, Y., Ogino, J., Yamashita, T., et al. (2010) Increased Caspase-2 Activity Is Associated with Induction of Apoptosis in IFN-Beta Sensitive Melanoma Cell Lines. Journal of Interferon \& Cytokine Research, 30, 349-357. http://dx.doi.org/10.1089/jir.2009.0015

[36] Robertson, J.D., Enoksson, M., Suomela, M., Zhivotovsky, B. and Orrenius, S. (2002) Caspase-2 Acts Upstream of Mitochondria to Promote Cytochrome c Release during Etoposide-Induced Apoptosis. The Journal of Biological Chemistry, 277, 29803-29809. http://dx.doi.org/10.1074/jbc.M204185200

[37] Manon, F., Favier, A., Nunez, G., Simorre, J.P. and Cusack, S. (2007) Solution Structure of NOD1 CARD and Mutational Analysis of Its Interaction with the CARD of Downstream Kinase RICK. Journal of Molecular Biology, 365, 160-174. http://dx.doi.org/10.1016/j.jmb.2006.09.067

[38] Hong, G.S. and Jung, Y.K. (2002) Caspase Recruitment Domain (CARD) as a Bi-Functional Switch of Caspase Regulation and NF-kappaB Signals. Journal of Biochemistry and Molecular Biology, 35, 19-23.

[39] Lamkanfi, M., Kanneganti, T.D., Van, D.P., Vanden, B.T., Vanoverberghe, I., Vandekerckhove, J., et al. (2008) Targeted Peptidecentric Proteomics Reveals Caspase-7 as a Substrate of the Caspase-1 Inflammasomes. Molecular \& Cellular Proteomics, 7, 2350-2363. http://dx.doi.org/10.1074/mcp.M800132-MCP200

[40] Lamkanfi, M. and Kanneganti, T.D. (2010) Caspase-7: A Protease Involved in Apoptosis and Inflammation. The International Journal of Biochemistry \& Cell Biology, 42, 21-24. http://dx.doi.org/10.1016/j.biocel.2009.09.013

[41] Hamsa, T.P. and Kuttan, G. (2010) Harmine Inhibits Tumour Specific Neo-Vessel Formation by Regulating VEGF, MMP, TIMP and Pro-Inflammatory Mediators Both in Vivo and in Vitro. European Journal of Pharmacology, 649, 64-73.

[42] Bratton, S.B., Walker, G., Srinivasula, S.M., Sun, X.M., Butterworth, M., Alnemri, E.S., et al. (2001) Recruitment, Activation and Retention of Caspases-9 and -3 by Apaf-1 Apoptosome and Associated XIAP Complexes. The EMBO 
Journal, 20, 998-1009.

[43] Eckelman, B.P. and Salvesen, G.S. (2006) The Human Anti-Apoptotic Proteins cIAP1 and cIAP2 Bind but Do Not Inhibit Caspases. Journal of Biological Chemistry, 281, 3254-3260. http://dx.doi.org/10.1074/jbc.M510863200

[44] Lindholm, P., Kuittinen, T., Sorri, O., Guo, D., Merits, A., Tormakangas, K., et al. (2000) Glycosylation of Phytepsin and Expression of dad1, dad2 and ost1 during Onset of Cell Death in Germinating Barley Scutella. Mechanisms of Development, 93, 169-173. http://dx.doi.org/10.1016/S0925-4773(00)00254-9

[45] Ter-Minassian, M., Wang, Z., Asomaning, K., Wu, M.C., Liu, C.Y., Paulus, J.K., et al. (2011) Genetic Associations with Sporadic Neuroendocrine Tumor Risk. Carcinogenesis, 32, 1216-1222. http://dx.doi.org/10.1093/carcin/bgr095

[46] Xiao, F., Widlak, P. and Garrard, W.T. (2007) Engineered Apoptotic Nucleases for Chromatin Research. Nucleic Acids Research, 35, e93. http://dx.doi.org/10.1093/nar/gkm486

[47] Kim, B.E., Lee, Y.H., Seong, C., Shin, S.Y., Lee, J.S., Cho, B.Y., et al. (2005) Salt Is Necessary for Nucleosomal DNA Fragmentation Induced by Caspase. Biotechnology Letters, 27, 1935-1942. http://dx.doi.org/10.1007/s10529-005-3906-z 